\title{
... Se inclina, gira, mas não vira ${ }^{+*}$
}

\author{
Deise M. Vianna ${ }^{1}$ \\ Universidade Federal do Rio de Janeiro \\ Instituto Oswaldo Cruz/Fiocruz \\ Conceição Barbosa-Lima \\ Universidade do Estado do Rio de Janeiro \\ Instituto Oswaldo Cruz/Fiocruz \\ Rio de Janeiro - RJ \\ Marco Adriano Dias \\ Instituto Federal do Rio de Janeiro \\ Nilópolis - RJ
}

\section{Resumo}

Apresentamos uma interação entre a Ciência e a Arte a partir do estudo do movimento de um modelo de caneca chamada "equilibrista" para melhor entendermos os conceitos físicos de equilíbrio de corpo rígido e suas aplicações no Design da caneca. Chamamos a atenção para uma relação entre diferentes condições de equilíbrio de duas canecas produzidas com materiais diferentes, cerâmica e cristal, mas com configurações bem semelhantes. Produzimos as cronofotografias de diversas posições iniciais das canecas a fim de estudar as condições de equilíbrio a partir de possíveis inclinações, com e sem líquido. Entendemos que estudos de Física a partir de objetos artísticos podem mostrar que ao nosso redor há Ciência e Arte se integrando e despertando interesse de alunos para o ensino e aprendizagem de Física.

Palavras-chave: Ensino de Física; Design; Equilíbrio; Ciência e Arte.

\footnotetext{
$+\ldots$ Leans, turns, but will not turn

* Recebido: novembro de 2018. Aceito: outubro de 2019.

${ }^{1}$ E-mails: deisevia@gmail.com; mcablima@uol.com.br; marco.dias@ifrj.edu.br
} 


\begin{abstract}
We present an interaction between Science and Artfrom the study of movement of a model of a mug called "equilibrist" to better understanding the physical concepts of equilibrium for a rigid body. We call attention to a relationship between different equilibrium conditions of two mugs produced with different materials, ceramic and crystal, but with similar configurations. We produced the chronophotos of several initial positions of the mugs in order to study the equilibrium conditions from possible inclines, with and without liquid. We understand that studies of Physics from artistic objects can show that around us have Science and Art integrating and arousing students' interest in the teaching and learning of Physics.
\end{abstract}

Keywords: Physics Education; Design; Equilibrium; Science and Art.

\title{
I. Como introdução
}

Este relato tem como objetivo mostrar a relevância do estudo de temas de Física em cursos de design e/ou artes

Durante o curso de desenho industrial, os alunos realizam projetos para outras disciplinas e a professora viu que em cima das carteiras de alguns deles haviam protótipos de diferentes objetos. Um deles, que estava sobre a carteira de um determinado aluno, era o protótipo de uma cabine telefônica muito interessante.

A professora pediu para ver o protótipo afirmando que o achara bastante interessante.

A partir daí se deu um diálogo mais promissor:

- Em que você pensou para idealizar esta cabine telefônica?

Ele respondeu que era uma questão de estética, que iria ser colocada na rua, então precisava ter uma boa aparência e acolher a pessoa ali dentro.

Era uma cabine telefônica tipo inglesa, fechada. Não exatamente as cabines vermelhas existentes em Londres, mas bastante semelhante.

A professora começou a levantar uma série de questões, começando por questioná-lo sobre o barulho externo que influenciaria a audição de quem estivesse dentro da cabine. Ao que o aluno respondeu que aquilo não poderia acontecer, que estava preservado, se a cabine estivesse fechada o barulho em seu interior não existiria.

A partir de então, a professora começou a discutir a questão dos materiais. Quais deles propagavam e quais não propagavam o som, afirmando que tais fenômenos eram estudados na acústica, uma parte da Física.

O diálogo continuou passando por diversos produtos existentes no mercado com a professora sempre apontando a parte da Física neles existentes. 
No entanto, o desentendimento, a importância e a relevância da disciplina Física para este tipo de curso é renovada a cada semestre, nos obrigando a buscar formas de estímulos variados para trazê-los ao estudo. O que é feito, em geral, apoiado em seus trabalhos de design, mas... aqueles que não buscam o entendimento e o aprendizado da Física corretamente podem incorrer na realização de um projeto como o representado a seguir, frase aliás que estamos bastante habituados a ouvir:

É correto afirmar que o estudo da disciplina Física facilita a elaboração de projetos com maior segurança quanto à possibilidade real de utilização do objeto projetado.

Neste caso, temos um olhar físico sobre um objeto de arte. Em que momento, aluno e professor podem pensar neste conjunto, se não os desafiamos a pensar e relacionar sobre os objetos ao seu redor.

De acordo com Bronowski (1998, p. 161), "o que faz a obra de arte encontrar uma abertura, uma faceta do caleidoscópio que sirva de porta para esse conhecimento", sendo assim podemos afirmar que...

\section{Design e Física - se completam}

Cachapuz (2007) escreve um artigo sobre Ciência e Arte e pergunta que papel estas duas atividades jogam na educação em ciências. Apropriamo-nos de algumas de suas ideias para prosseguir em nossa introdução.

Logo de pronto o autor afirma ser o tema das relações dialógicas entre Arte e Ciência complexo e que pode ser abordado sob diferentes formas.

Se chamarmos à colaboração Bachelard (1957, apud Cachapuz 2007, p.288) veremos que o filósofo considerava que a emoção estética está no cruzamento da descoberta científica e da criação artística, ou seja, "admira primeiro, compreenderás em seguida".

Vigotski (2009), citando Ribot, diz:

Nas ciências, diz Ribot, a imaginação numérica não se reveste de mitos semelhantes. Acusam a ciência de reprimir, com o seu desenvolvimento, a imaginação, quando, na verdade, ela abre áreas incomparavelmente mais amplas para sua criação (p. 39).

Continuando, na mesma página leremos que “(...) o exagero, assim como a imaginação, em geral, é necessário tanto na Arte quanto na Ciência” (p. 39).

Smolka (2009), que comenta a obra de Vigotski nos diz:

No que se refere às práticas pedagógicas, no entanto, trata-se do incansável trabalho de inventar e planejar, a cada dia, como viabilizar, de maneira mais efetiva, o acesso das crianças ao conhecimento produzido e sua produção histórico-cultural (p. 23). 
Nesta citação de Smolka, podemos sem riscos alterar a palavra crianças para estudantes, posto que a tarefa é semelhante, senão a mesma.

Além das questões de criatividade e da relação Ciência e Arte, devemos ressaltar outro de nossos referenciais teóricos: as atividades investigativas. Colocar um problema para um aluno faz com que ele pense e vá em busca de respostas. Não cabe ao professor indicar todo o caminho, mas colocá-lo diante de um problema (questão, objeto, fenômeno) e perguntar sobre as principais variáveis envolvidas e dar-lhe liberdade para pensar (SASSERON; MACHADO, 2017). Este procedimento é típico tanto da investigação científica, como da Arte.

No caso em estudo, estamos trabalhando com uma das representações artísticas - design.

\title{
III. E o que é Design?
}

Uma simples definição de design é colocada por Miller (1988) através da frase:

"Design é o processo de pensamento que compreende a criação de alguma coisa".

E em quase todas as coisas há um princípio físico que está dando suporte.

Sem dúvida esta definição é bastante sintética e, segundo seu autor, exprime a essência do design. Mas ao longo de seu texto, ele pontua com várias frases as características desta atividade. As palavras que apoiam tais frases dispersas ao longo do texto são: processo de pensamento; intuição e razão. Sendo assim, o design é a síntese de três aspectos do pensamento: insigth, intuição e razão.

Lendo o artigo de Boni, Silva e Silva (2014) falando sobre as diversas definições de design podemos ressaltar, através das palavras dos autores que:

\begin{abstract}
A emoção, cognição e estética devem beneficiar a sociedade em diversos aspectos de seu cotidiano, como trabalho, lazer e outros. (...) Através do pensamento abstrato e das inspirações, o designer deve concretizar produtos e serviços que sejam voltados ao ser humano, isto é, ter as reais necessidades do homem como base para o projeto (HUNTER, 2013). Em termos gerais, podemos assumir o posicionamento de Miller (2004), quando diz que o design é o processo de pensamento que compreende a criação de uma entidade (p. 4).
\end{abstract}

Se o designer deve concretizar produtos e serviços que sejam voltados ao ser humano, como afirma Hunter na citação acima, ainda deve executar uma atividade técnicocientífica, criativa e artística.

Mas podemos reduzir o design a um de seus aspectos? A Arte?

Quem nos responde é Bonsiepe (2011) que, olhando o senso comum, afirma que "o termo design está fortemente associado às atividades estético-formais". Em nossas palavras em objetos funcionais com características marcadamente artísticas. 


\section{E com esses olhos de senso comum...}

Entramos em uma destas lojinhas de museu... De repente nossos olhos foram atraídos para umas peças que na hora chamamos de "canequinhas". Havia vermelhas, pretas, brancas e de cristal. Começamos a olhá-las com atenção e verificamos, com a indicação da vendedora que aquele objeto permanecia em equilíbrio qualquer que fosse a posição que nós o colocássemos. Olhamos, mexemos, inclinamos, giramos... e não caía. (Embora a vendedora já tivesse dito... tivemos que experimentar, testar..., afinal, temos que investigar o fenômeno para termos "dados"). Compramos para estudarmos os movimentos do objeto. Quando mostramos para alguns amigos e amigas físicos eles ficaram como nós interessados na "canequinha". Portanto, "brincamos" rodando, virando... e não caía.

Na literatura sobre Arte, destacamos as palavras de Scruton (2017): “é como se, ao descrever a relação da obra de Arte com outras coisas (por exemplo, com a maneira como a ousadia de um gesto pode contrabalançar a debilidade do outro), alguém estivesse tentando mostrar que a obra possui alguma propriedade em comum com essas outras coisas" (p. 100). No olhar da Ciência, não é só uma experiência estética, mas sim uma experiência em sua integralidade.

\section{Estudando os objetos...}

Propusemos basicamente duas questões:

- Como a massa da caneca está distribuída em sua forma geométrica?

- Existe um limite de inclinação para as canecas sem líquido? E com líquido?

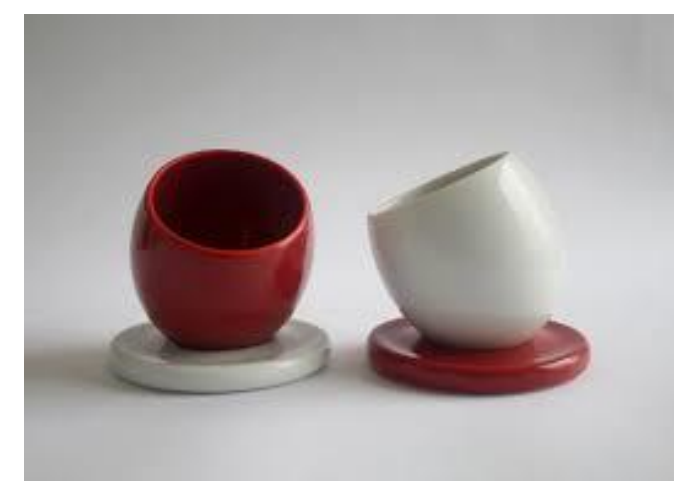

Fig. 1 - Dois equilibristas de cerâmica. Fonte: Reboh Design. 


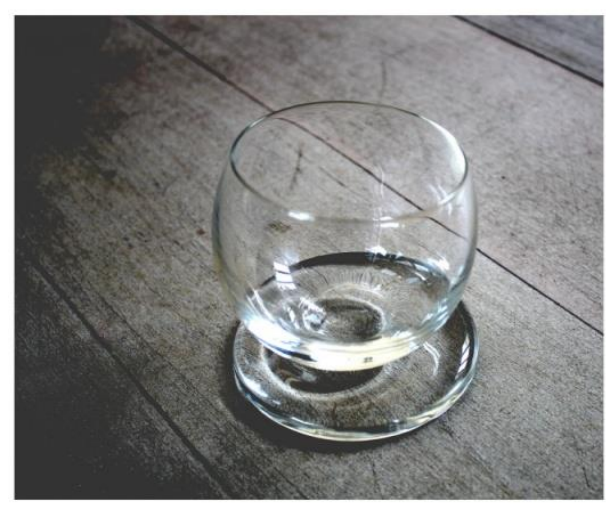

Fig. 2 - Um equilibrista de cristal.Fonte: Reboh Design.

Encontramos a designer criadora do objeto - Suzanne Reboh ${ }^{2}$. Ela aprovou a ideia da realização de um estudo dos fenômenos físicos envolvendo seu objeto, assim como, colocouse à disposição para auxiliar no que julgássemos necessário. Então, começamos a trocar mensagens e aprendemos como eles haviam sido construídos e chamados pela autora de Equilibristas! Apropriamo-nos, inclusive, de uma frase que existe em seu site (www.rebohdesign.com) para título de nosso trabalho: ... Se inclina, gira, mas não vira...

Assim, partimos para a nossa investigação, que é uma atividade especializada de caráter técnico-científico, criativo e artístico.

De acordo com as informações da artista, Reboh (2017), fornecidas através de $e$ mails trocados entre nós e ela, nossas duas últimas perguntas (- Qual a diferença das canecas em cerâmica e as em cristal? Qual a função do prato de apoio?) são respondidas diretamente por ela.

Os processos para a porcelana (equilibrista para cafés) e do cristal (equilibrista cristal) são diferentes entre si.

No caso específico da porcelana, o método utilizado é o da olaria. Usa barbotina (pasta cerâmica líquida, mistura de argila e água, utilizada para produzir peças cerâmicas utilitárias e para fazer os moldes de vazamento de metais fundidos) e moldes de gesso. O método é de enchimento do molde e derramamento do excesso depois de formar a nata. Por esta razão, também, a parede é homogênea, não tem como fazer o fundo mais espesso.

E para manter o equilíbrio, o prato se faz necessário, mas serve também como porta copos e para brincar com o equilíbrio.

No caso do equilibrista cristal, o produto é bem artesanal, soprado, usando cristal líquido. Por esta razão, conseguimos ter graduação de espessura no copo, onde o fundo é mais espesso. Neste caso, o copo não vira mesmo fora do prato, pois tem um centro de gravidade bem formado.

\footnotetext{
${ }^{2} \mathrm{~A}$ artista nos atendeu prontamente por e-mail e nos deu informações. É uma designer premiada e com várias exposições no Brasil e exterior.
} 
O prato serve como porta copos base para bebidas geladas ou quentes, e para poder brincar com os ângulos de inclinação.

Estas explicações de Reboh (2017) já respondem inicialmente à nossa primeira pergunta: Qual a distribuição da massa da "caneca"? Seguiremos oferecendo algumas medidas feitas pelos autores deste trabalho.

As dimensões do equilibrista, tanto o de cerâmica, quanto o de cristal, foram medidas com um paquímetro. Abaixo seguem as tabelas comparativas entre o equilibrista de cerâmica e o de cristal dos respectivos dados:

As dimensões do equilibrista de cristal e de cerâmica, mostrado nas Fig. 2 e 3, e medidas em centímetros, são as que seguem:

Quadro 1: Dimensões dos equilibristas de cristal e cerâmica.

\begin{tabular}{|l|l|l|}
\hline Dimensões & $\begin{array}{l}\text { Cristal } \\
(\mathrm{cm})\end{array}$ & $\begin{array}{l}\text { Cerâmica } \\
(\mathrm{cm})\end{array}$ \\
\hline Diâmetro externo da borda & 7,5 & 6,5 \\
\hline Diâmetro interno da borda & 7,1 & 5,8 \\
\hline Altura externa & 8,7 & 7,1 \\
\hline Altura interna & 7,5 & 6,9 \\
\hline Espessura da borda & 0,2 & 0,4 \\
\hline
\end{tabular}

Fonte: os Autores.

Os volumes dos recipientes totalmente cheios são:

$\mathrm{V}_{\text {cristal }}=300 \mathrm{ml} \mathrm{V}$ cerâmica $=150 \mathrm{ml}$.

O prato de apoio do equilibrista de cristal apresenta as seguintes dimensões: diâmetro total, 9,4 cm; e, diâmetro do rebaixamento central do prato, 3,4 cm. Para o de cerâmica são: $9,1 \mathrm{~cm} \mathrm{e} \mathrm{4,1,} \mathrm{respectivamente.}$

\section{V.1 Os comportamentos do "Equilibrista"}

Com o objetivo de respondermos à nossa segunda pergunta: Existe um limite de inclinação para as canecas sem líquido? E com líquido?, fizemos alguns ensaios e registramos o comportamento do "Equilibrista" em cada situação.

Quando postas sobre suas bases, as canecas equilibristas de cerâmica e de cristal possuem comportamentos semelhantes para o equilíbrio. Uma vez que elas repousam na posição em que são colocadas sobre suas bases, ambas permanecem em equilíbrio estável. Porém, as diferenças nas distribuições de massa entre as canecas de cerâmica e de cristal fazem com que elas tenham comportamentos distintos em relação ao equilíbrio, quando colocadas fora das suas bases de apoio. 
A fim de ilustrar essas diferenças nos comportamentos das canecas em relação ao equilíbrio, realizamos um experimento, registrado cronofotograficamente ${ }^{3}$, cujos resultados são apresentados na Fig. 3.

Inicialmente as canecas, vazias, foram posicionadas verticalmente (Fig. 3A) e em seguida deslocadas de suas posições para uma posição diagonal (Fig. 3B), com o intuito de que elas fossem abandonadas a partir dessa posição. Mas, como podemos observar nessa figura, a caneca de cristal manteve-se na posição diagonal enquanto estava sob a ação da força do dedo da pessoa que fez o experimento, por outro lado, a caneca de cerâmica logo tombou, evidenciando não existir uma tendência desta última em restaurar sua posição vertical.

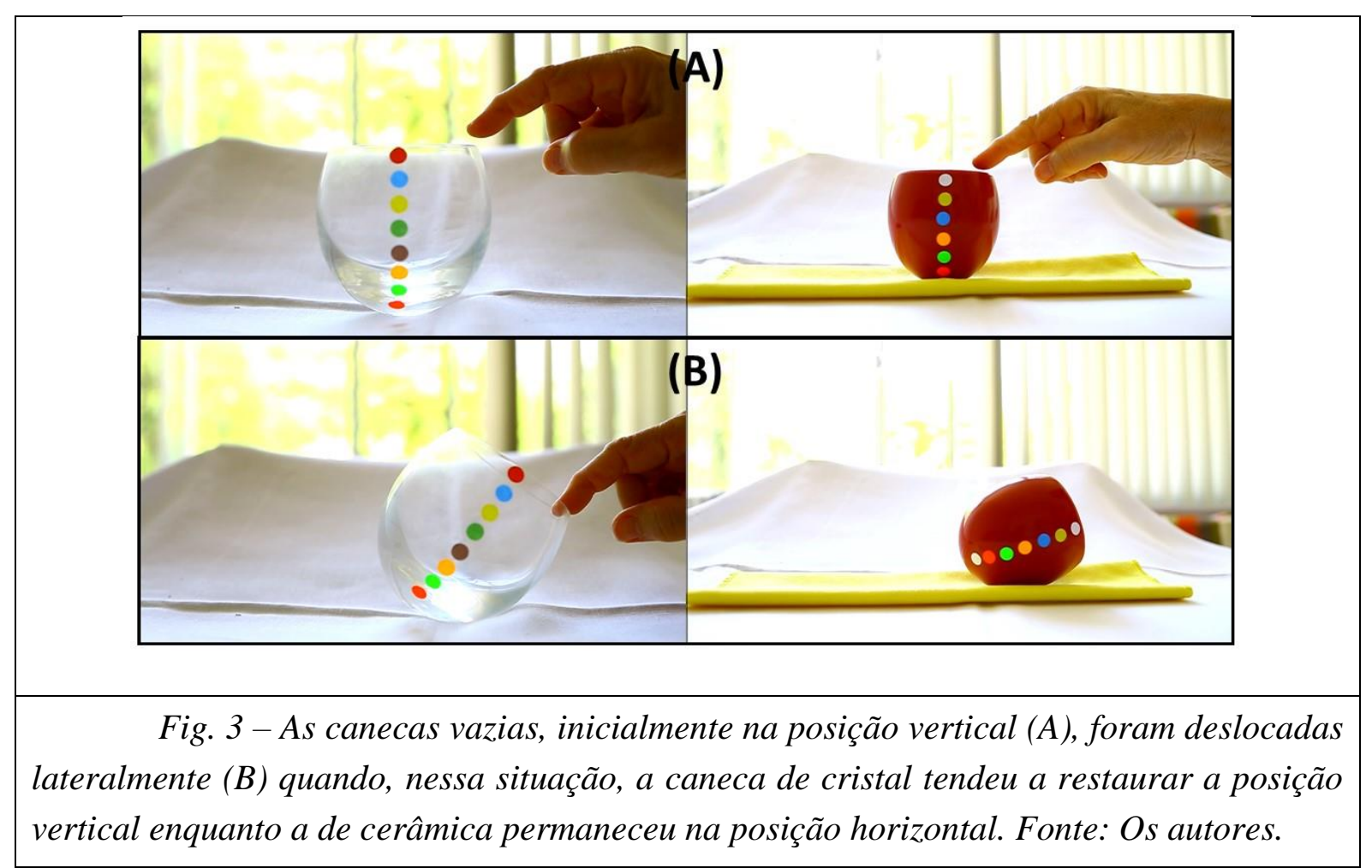

$\mathrm{Na}$ Fig. 4, apresentamos as cronofotografias dos movimentos das canecas sem estarem em seus apoios. Para compreender os comportamentos em relação ao equilíbrio, inserimos adesivos coloridos numa disposição vertical para que pudéssemos observar o movimento em uma fotografia, ou seja, produzimos o registro cronofotográfico dos movimentos das canecas. Nessas cronofotografias, verificamos que houve uma tendência de restauração da posição vertical para a caneca de cristal (Fig. 4A), ao passo que não houve essa tendência na caneca de cerâmica (Fig. 4B).

\footnotetext{
${ }^{3}$ Cronofotografia: Registro espaço-temporal da trajetória de um objeto.
} 


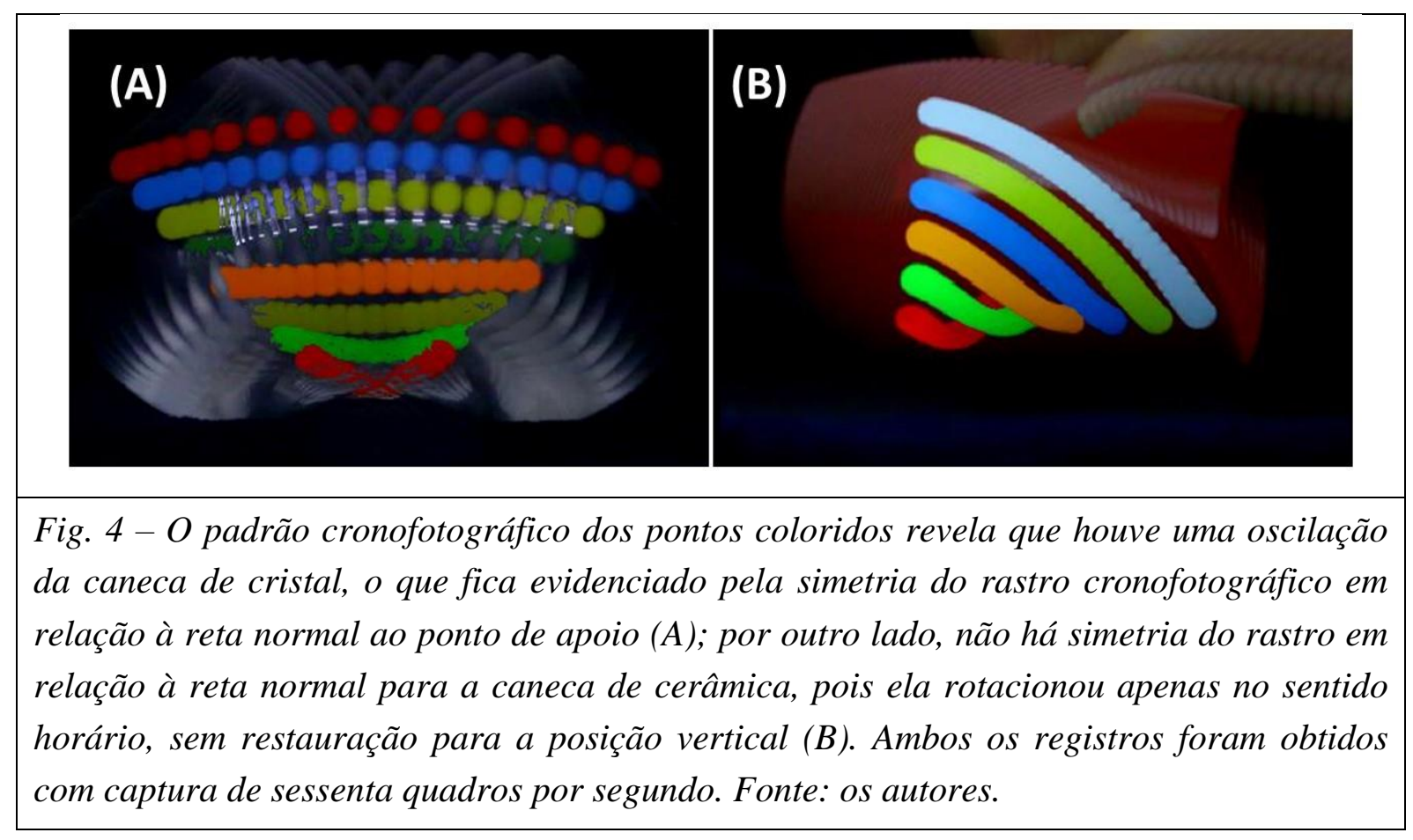

Mas, por que isso acontece? Porque a caneca de cristal tende ao equilíbrio na posição vertical enquanto vazia, mas a de cerâmica não? Será que elas apresentam o mesmo comportamento quando cheias?

A explicação do porquê as canecas vazias apresentam comportamentos distintos pode ocorrer a partir de dois fatores intrínsecos: a distribuição de massa nas canecas e as suas geometrias externas. Como podemos observar na Fig. 5, apesar de ambas possuírem semelhança nas suas geometrias externas, a caneca de cristal possui uma distribuição de massa muito maior na porção inferior do que a distribuição de massa da caneca de cerâmica. O resultado prático dessa diferença entre as distribuições de massa é que, na caneca de cristal, o centro de massa é mais rasteiro, ao passo que na de cerâmica ele é mais elevado.

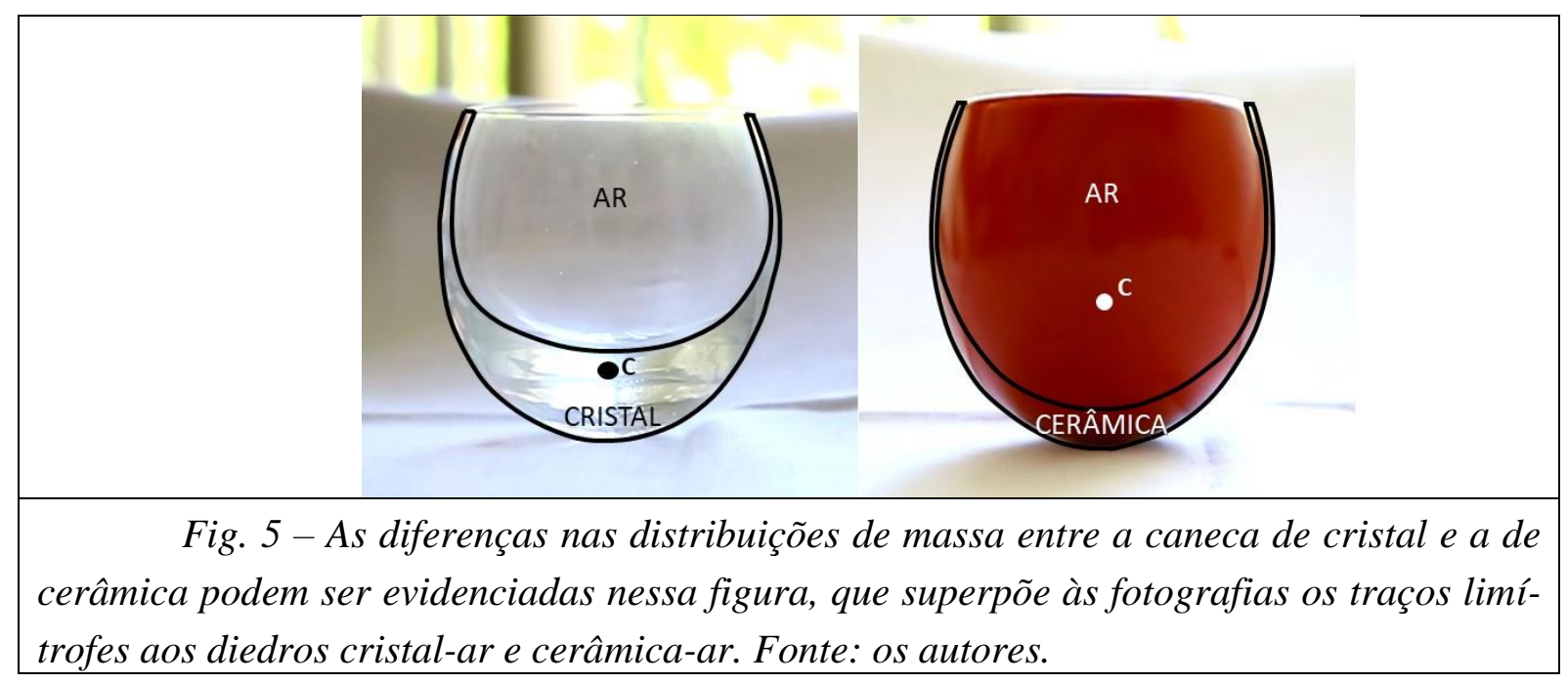

Caderno Brasileiro de Ensino de Física, v. 36, n. 3, p. 841-853, dez. 2019. 
Dessa forma, quando deslocamos as canecas de suas posições verticais ocorrem duas situações distintas, representadas na Fig. 6. Em relação à caneca de cristal, qualquer que seja o deslocamento angular impresso a ela, o centro de massa, ponto $\mathrm{C}$ na figura, permanecerá ao lado do fundo do copo em relação à reta normal ao ponto de contato entre a caneca e a superfície onde a caneca está (segmento tracejado na Fig. 6). Com isso, o peso da caneca - força de interação gravitacional entre a massa da caneca e a massa da Terra, que tem como ponto de ação o seu centro de massa - realiza um torque restaurador para qualquer que seja o ângulo de inclinação desta. Como resultado, a caneca sempre gira no sentido horário caso consideremos a situação representada na Fig. 6A. Por outro lado, devido à diferença na distribuição de massa na caneca de cerâmica, seu centro de massa ocupa uma posição mais elevada em relação àquela na caneca de cristal (estamos considerando a geometria externa das canecas como análogas). Isso faz com que exista um ângulo limite para o qual o centro de massa dessa caneca translade a reta normal à superfície de contato. O efeito prático é que o peso restaura a posição vertical apenas para os ângulos de inclinação inferiores a esse ângulo limite; a partir deste ângulo, a força peso tende a rotacionar a caneca no sentido anti-horário, como representado na Fig. 6B.

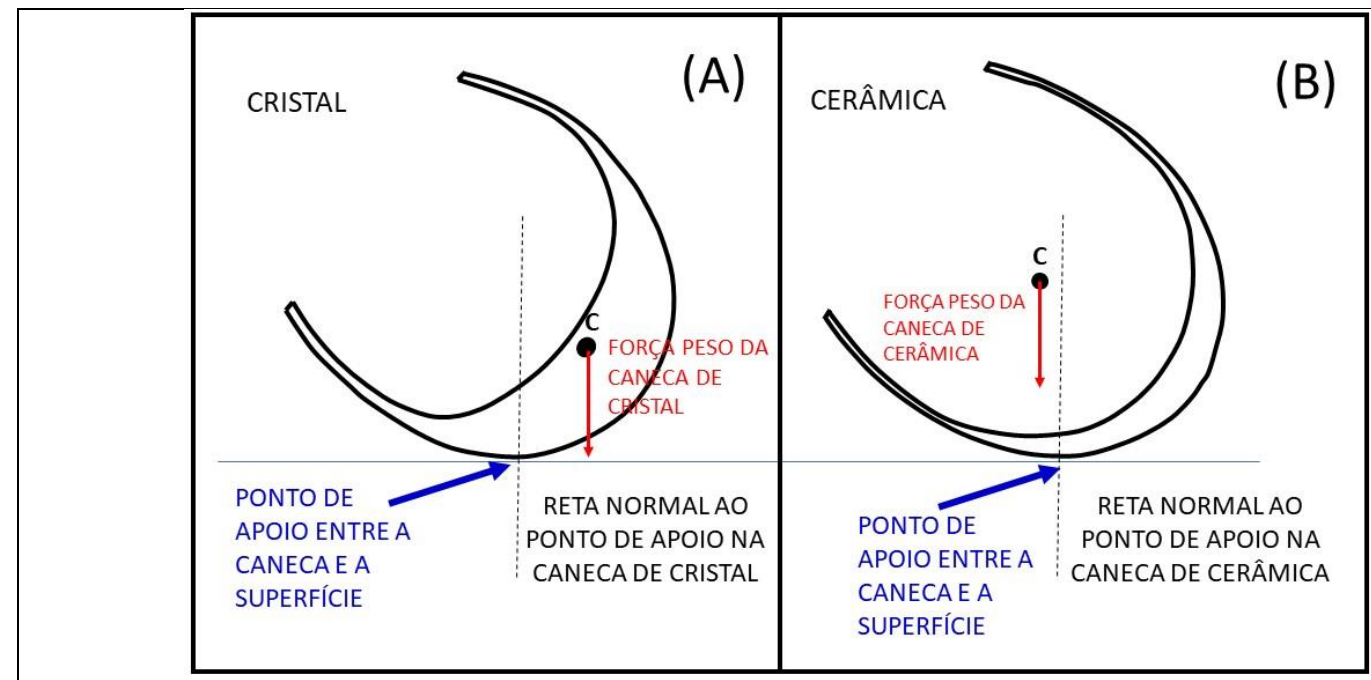

Fig. 6 - Representa uma secção reta do equilibrista de cristal e de cerâmica, mostrando que no de cristal a força peso sempre restaura o equilíbrio da caneca, enquanto na de cerâmica o equilíbrio pode ocorrer em uma posição qualquer. Fonte: Os autores.

\section{V.2 Mas será que observamos esses mesmos comportamentos com as canecas cheias?}

A fim de verificar o comportamento das canecas equilibristas quando cheias e fora das suas bases de apoio, refizemos o experimento anterior para diversos volumes de líquido na caneca, porém, usamos somente a caneca de cristal por uma facilidade de visualização cronofotográfica. Nossa hipótese era que seria um tanto arriscado para a pessoa degustadora utilizar a caneca fora da sua base, ficando, assim, sujeita às leis naturais que poderiam implicar 
num derramamento e todos os transtornos e prejuízos pessoais e sociais que esse tipo de incidente etílico possa provocar. Ou seja, em nossa prévia concepção, haveria uma inclinação máxima para a caneca cheia, a partir da qual, no movimento de oscilação, o líquido transbordaria. Mas a natureza nos surpreendeu.

Ao deslocarmos a caneca até o limite máximo permitido pelo volume de líquido em seu interior sem que o mesmo transbordasse, verificamos que a caneca oscilava sem derramamento de líquido, para qualquer que fosse o volume. Representamos esses resultados na Fig. 7, correspondente a um volume de $150 \mathrm{~mL}$ de leite.

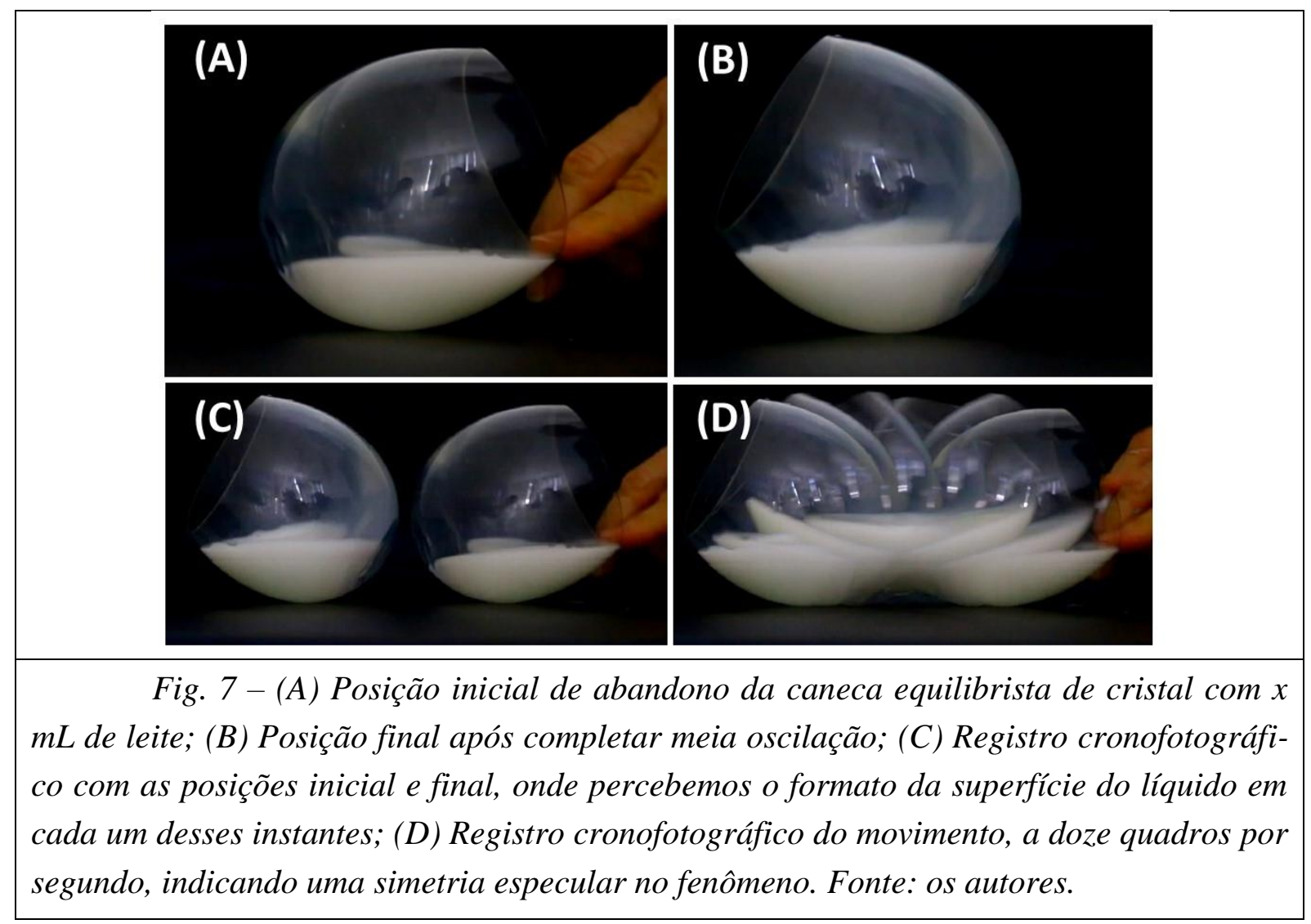

Os resultados indicam que há uma predominância de duas interações no sistema composto por caneca, líquido e Terra, e, soma-se a essas interações, um princípio universal de tudo aquilo que tem massa: a inércia. Como discutido anteriormente para os experimentos com caneca vazia, a oscilação é resultado da ação da força peso que atua sobre o centro de massa do sistema que, com a caneca inclinada, é deslocado em relação ao ponto de apoio da caneca na superfície. Porém, com a presença do líquido no sistema, devemos considerar a interação deste com a superfície interna da caneca, resultado da viscosidade do fluido que, no caso da caneca, sempre é predominantemente composto por água. Numa conclusão conceitual, o peso oscila, o atrito viscoso arrasta o líquido durante a oscilação e a inércia do líquido faz com que ele tenda a permanecer na posição inicial de abandono. Para a sorte dos usuários, essas três "forças da natureza" se harmonizam com a geometria da caneca equilibrista, garan- 
tindo assim que o líquido em seu interior permaneça a salvo de derramamentos indesejáveis mesmo quando fora da sua base.

\section{Onde nós chegamos...}

Discutimos nossa curiosidade com um produto artístico e a interpretação dos fenômenos com o olhar científico. Juntamos Arte com Ciência.

Buscamos mostrar que a Arte e, principalmente o Design, são criados e/ou construídos com princípios de Física, que nem sempre são destacados em aulas pelos professores, nem de Física e nem de Arte. São produtos que vemos cotidianamente e nem nos damos conta da Ciência que está por trás e pode (deve) ser levada para sala de aula.

Embora tenhamos agregado nosso conhecimento de Física à beleza do objeto "Equilibrista", não obrigatoriamente a visão do senso comum sobre a arte está descartada, assim como a visão científica da Física. Cada um dos conhecimentos específicos caminha de acordo com as suas características, contudo o entrelaçamento das duas áreas aponta para a possibilidade de um ensino-aprendizagem mais integrado.

Citando Zamboni (2001, p.20) “... A criação, na realidade é um ordenamento, é selecionar, relacionar e integrar elementos, que a princípio pareciam impossíveis".

Nosso objetivo foi o de introduzir fotos e interpretações físicas para corpos não somente desenhados e hipotéticos, mas que fazem parte de nosso uso diário, com intenso chamamento para desvendarmos seu comportamento.

Portanto: bom café ou bom drink!!!

\section{Agradecimentos}

Os autores desejam expressar seus mais profundos agradecimentos à Sra. Susanne Reboh por sua autorização e também pela sua integração e interesse em nosso trabalho.

\section{Referências}

BONSIEPE, G. Design, cultura e sociedade São Paulo: Blucher, 2011.

BRONOWSKI, J. O olho visionário. Brasília: Ed. UnB, 1998.

CACHAPUZ, A. F. Arte e ciência: que papel na educação em ciência? Revista Eureka sobre Enseñanza y Divulgación de las Ciencias, v. 4, n. 2, p. 287-294, 2007.

MILLER, W. R. A definição de design. Tradução: LEITE, J. de S. Disponível em: <feiramoderna.net/ufes/projeto1/MILLER-A-definicao-de-design.pdf>. Acesso em: 04 ago. 2017.

REBOH, S. Mensagens eletrônicas trocadas entre os autores e a designer, 2017. 
SASSERON, L.; MACHADO, V. F. Alfabetização científica na prática: inovando a forma de ensinar Física. São Paulo: livraria da Física, 2017. 100p. v. 1.

SCRUTON, R. Arte e imaginação: um estudo em filosofia da mente. São Paulo: É Realizações Editora, 2017.

SMOLKA, A. L. Comentários. In: Imaginação e criação na infância. 3. ed. São Paulo: Ática, 2009.

VIGOTSKI, L. S. Imaginação e criação na infância. 3. ed. São Paulo: Ática, 2009.

ZAMBONI, S. A pesquisa em arte. Campinas: Autores Associados, 2001.

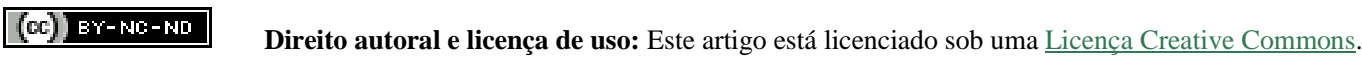

